\title{
The relationship between right-sided tumour location, tumour microenvironment, systemic inflammation, adjuvant therapy and survival in patients undergoing surgery for colon and rectal cancer
}

\author{
Meera Patel ${ }^{\star, 1,2}$, Stephen T McSorley ${ }^{1}$, James H Park ${ }^{1}$, Campbell S D Roxburgh ${ }^{1}$, Joann Edwards ${ }^{2}$, \\ Paul G Horgan ${ }^{1}$ and Donald C McMillan ${ }^{1}$ \\ ${ }^{1}$ Academic Unit of Surgery, School of Medicine, University of Glasgow, Royal Infirmary, Glasgow G31 2ER, UK and ${ }^{2}$ Unit of \\ Experimental Therapeutics, Institute of Cancer Sciences, University of Glasgow, Garscube Estate, Glasgow G61 1QH, UK
}

Background: There has been an increasing interest in the role of tumour location in the treatment and prognosis of patients with colorectal cancer (CRC), specifically in the adjuvant setting. Together with genomic data, this has led to the proposal that rightsided and left-sided tumours should be considered as distinct biological and clinical entities. The aim of the present study was to examine the relationship between tumour location, tumour microenvironment, systemic inflammatory response (SIR), adjuvant chemotherapy and survival in patients undergoing potentially curative surgery for stage I-III colon and rectal cancer.

Methods: Clinicopathological characteristics were extracted from a prospective database. MMR and BRAF status was determined using immunohistochemistry. The tumour microenvironment was assessed using routine H\&E pathological sections. SIR was assessed using modified Glasgow Prognostic Score (mGPS), neutrophil:lymphocyte ratio (NLR), neutrophil:platelet score (NPS) and lymphocyte:monocyte ratio (LMR).

Results: Overall, 972 patients were included. The majority were over 65 years (68\%), male (55\%), TNM stage II/III (82\%). In all, 40\% of patients had right-sided tumours and $31 \%$ had rectal cancers. Right-sided tumour location was associated with older age $(P=0.001)$, deficient MMR $(P=0.005)$, higher $T$ stage $(P<0.001)$, poor tumour differentiation $(P<0.001)$, venous invasion $(P=0.021)$, and high $\mathrm{CD}^{+}$within cancer cell nests $(P=0.048)$. Right-sided location was consistently associated with a high $\mathrm{SIR}$, mGPS $(P<0.001)$ and NPS $(P<0.001)$. There was no relationship between tumour location, adjuvant chemotherapy $(P=0.632)$ or cancer-specific survival (CSS; $P=0.377)$. In those 275 patients who received adjuvant chemotherapy, right-sided location was not associated with the MMR status $(P=0.509)$ but was associated with higher $T$ stage $(P=0.001)$, venous invasion $(P=0.036), C D 3^{+}$at the invasive margin $(P=0.033)$ and $C D 3^{+}$within cancer nests $(P=0.012)$. There was no relationship between tumour location, SIR or CSS in the adjuvant group.

Conclusions: Right-sided tumour location was associated with an elevated tumour lymphocytic infiltrate and an elevated SIR. There was no association between tumour location and survival in the non-adjuvant or adjuvant setting in patients undergoing potentially curative surgery for stage I-III colon and rectal cancer.

*Correspondence: M Patel; E-mail: meera.patel@glasgow.ac.uk

Received 6 October 2017; revised 9 November 2017; accepted 10 November 2017; published online 16 January 2018

(C) 2018 Cancer Research UK. All rights reserved 0007-0920/18 
Worldwide, colorectal cancer (CRC) is the third most common cancer in men and the second most common in women with over half of cases occurring in developed nations (IARC, 2012). In the United Kingdom 5-year survival for patients diagnosed with CRC is $\sim 60 \%$ (Cancer Research UK, 2011). Several population-based studies and data from clinical trials have reported that primary tumour location provides prognostic value in terms of patient survival. Over the last few decades most epidemiological studies from western populations report a continued rightward shift of CRC (Alley and McNee, 1986; Cucino et al, 2002; Fleshner et al, 1989). Cancers of the right colon are more likely to be diagnosed in patients who are older and female; they are associated with locally advanced tumours, with greater mucinous component, poor differentiation-deficient mismatch repair (MMR) and BRAF V600E mutation (Alley and McNee, 1986; Fleshner et al, 1989; Clarke and Kopetz, 2015; Weiss et al, 2016; Gelsomino et al, 2016).

The clinical and biological distinction between colon and rectal cancer is widely recognised. Although several studies report that right- and left-sided colonic tumours should be considered as a distinct biological entity, the debate about the clinical relevance of this is ongoing. Moreover, the clinical utility of this distinction remains unclear with little evidence of its relevance to patients with stage I-III potentially curable colon cancer in terms of diagnosis, treatment and follow-up. The benefit of fluorouracil-based adjuvant therapy in CRC is widely recognised; however, in metastatic disease it would appear that right-sided colonic tumours are less responsive to such chemotherapy (Venook et al, 2016). Therefore, a plausible hypothesis is that the prognostic value of tumour location in patients with operable colorectal cancer is dependent on other unmeasured confounding factors. There is a substantial body of evidence that recognises systemic inflammation (Li et al, 2014; Woo et al, 2015) and the tumour microenvironment as important determinants of disease progression and outcome in both colon and rectal cancer. Inflammation-based prognostic scores that evaluate the systemic inflammatory response (SIR; $\mathrm{Li}$ et al, 2014; Park et al, 2016) and the tumour microenvironment (Klintrup et al, 2005; Roxburgh and McMillan, 2012) have yielded prognostic value independent of the widely used TNM staging system and so are candidates as potential confounding factors. The aim of the present study was to examine the relationship between tumour location, tumour microenvironment, systemic inflammation, adjuvant therapy and survival in patients undergoing potentially curative surgery for stage I-III colon and rectal cancer.

\section{MATERIALS AND METHODS}

Clinicopathological characteristics. Patients were identified from a prospectively collated database of patients undergoing surgery for CRC in a single surgical unit at the Glasgow Royal Infirmary between 1997 and 2016. Patient exclusions were based on the following criteria: metastatic disease including those patients with peritoneal involvement, emergency surgery, surgery with palliative intent, surgery for inflammatory bowel disease-related malignancy, neoadjuvant chemoradiotherapy (excluded due to the potential immunological impact on the tumour microenvironment), familial cancer syndrome, underlying inflammatory condition or mortality within 30 days of surgery. Patients with tumours proximal to the splenic flexure were considered as right-sided. Tumours were staged according to conventional TNM classification with additional data retrieved from pathological reports issued after resection. Routine pathological elastica staining was used to assess the presence of venous invasion (Roxburgh et al, 2010). Following surgery patients were discussed at a local multidisciplinary meeting. Those patients undergoing colonic or rectal surgery with stage III or high-risk stage II disease without significant comorbidity were offered 5-fluorouracil-based adjuvant chemotherapy with or without oxaliplatin, based on the guidelines at the time.

Patients were routinely followed up for 5 years after surgery. Date and cause of death were crosschecked with the cancer registration system and the Registrar General (Scotland). Death records were complete until 1 May 2016; this acted as the censor date for survival analysis. Cancer-specific survival (CSS) was measured from the date of surgery until the date of death from recurrent or metastatic CRC. Overall survival (OS) was measured from date of surgery until date of death from any cause.

Assessment of MMR and BRAF status. A subset of the patients in the full cohort underwent evaluation of the MMR status, BRAF status and assessment of the tumour microenvironment. Using immunohistochemistry, a previously constructed tissue microarray comprising cores of formalin-fixed paraffin-embedded cancer tissue was used to assess MMR and BRAF status. Immunohistochemistry for MMR status was previously described (Park et al. 2016). MMR protein expression was reported as MMR-competent or -deficient by a single blinded observer.

For assessment of BRAF status tissue microarrays were dewaxed in xylene and rehydrated with graded alcohols. Antigen retrieval was performed using Tris-EDTA buffer at $\mathrm{pH} 9$ under pressure for $5 \mathrm{~min}$. Endogenous peroxidase activity was blocked using 3\% hydrogen peroxide for $10 \mathrm{~min}$. Casein (10\%) was applied for $20 \mathrm{~min}$ as a blocking solution. Tissue microarrays were incubated overnight at $4{ }^{\circ} \mathrm{C}$ with antihuman BRAF V600E mouse monoclonal antibody (clone VE1, Spring Biosciences, USA) at a concentration of $1: 200$. After washing in TBS, Envision (Dako) was applied for $30 \mathrm{~min}$ at room temperature before washing in TBS again. DAB substrate was added for $5 \mathrm{~min}$ until colour developed before washing in running water for $10 \mathrm{~min}$. Slides were then counterstained in haematoxylin for $60 \mathrm{~s}$ and blued with Scotts' tap water before being dehydrated through a series of graded alcohols. Coverslips were applied using distrene, plasticizer, xylene (DPX). BRAF V600E mutation was reported as absent or present by a single blinded observer.

Assessment of the tumour microenvironment. Assessment of the tumour microenvironment was performed using routine haematoxylin and eosin-stained tissue sections. KlintrupMäkinen (KM) score (low/high) and extent of tumour stroma was assessed using tumour stroma percentage $(\leqslant 50 \%$ low or $\geqslant 50 \%$ high), both previously described (Klintrup et al, 2005; Mesker et al, 2007). Tissue sections were also used to assess lymphocytic tumour infiltrate. Immunohistochemistry for $\mathrm{CD}^{+}$ (mature) and $\mathrm{CD}^{+}$(cytotoxic) T-lymphocytes was performed as per the methodology previously described (Richards et al, 2014). T-lymphocyte density at the invasive margin and within the cancer cell nests was semiquantitatively graded as low or high. Investigators were blinded to clinical data, pathological data and survival outcome.

All cases were co-scored by a second investigator to ensure consistency of scoring.

Assessment of the SIR. Serum CRP, albumin and differential white cell count were measured within 30 days before surgery and recorded prospectively. Preoperative SIRs were defined using the modified Glasgow Prognostic Score (mGPS), the neutrophil:lymphocyte ratio (NLR), the neutrophil:platelet score (NPS) and lymphocyte:monocyte ratio (LMR). The mGPS was constructed as described previously (McMillan, 2013; patients with CRP $\leqslant 10 \mathrm{mg} / 1$ scored $0, \quad \mathrm{CRP}>10 \mathrm{mg} / \mathrm{l}$ scored 1 and CRP $>10 \mathrm{mg} /$ and albumin $<35 \mathrm{~g} / \mathrm{L}$ scored 2 ). On the basis of previously published thresholds, NLR $>5$ was considered elevated (Guthrie et al, 2013). The NPS was calculated as previously described (Watt et al, 2015), platelet count $<400 \times 10^{9} / 1$ and neutrophil count $<7.5 \times 10^{9} / 1$ 
scored 0 , either a neutrophil count $>7.5 \times 10^{9} / 1$ or platelet count $>400 \times 10^{9} / 1$ scored 1 , and those with elevated neutrophils and platelets scored 2 . LMR was considered as either low $(\leqslant 2.38)$ or high (>2.38) as previously described (Chan et al, 2017).

The patient characteristic data in the present study were collected as part of a prospective clinical audit of patients undergoing surgery for CRC in Glasgow Royal Infirmary. Tissue assessment of MMR and BRAF status and the tumour microenvironment was carried out with informed consent. Approval for the audit and for the tissue analysis was given by The West of Scotland Research Ethics Committee.

Statistical analysis. The association between tumour location and clinicopathological characteristics, measures of the tumour microenvironment and measures of systemic inflammation were analysed using the $\chi^{2}$-test. Five-year cancer-specific and OS was examined using Kaplan-Meier log-rank survival analysis and univariate Cox-proportional hazards regression to calculate hazard ratios (HR) and 95\% confidence intervals. Variables found to be statistically significant $(P<0.05)$ on univariate analysis were entered into a Cox regression multivariate model using a backward conditional method. A $P$-value of $<0.05$ was considered to be significant. Analyses were performed using SPSS software version 21 (IBM SPSS).

\section{RESULTS}

Full cohort. Overall, 972 patients who underwent elective surgery with curative intent for stage I-III CRC between January 1997 and 2016 were included in the analysis. Clinical and pathological features are shown in Table 1. Two-thirds of the patients included were over the age of 65 and 55\% were male. In all, 178 (18\%) patients had TNM stage I disease, 437 (45\%) had stage II disease and $356(37 \%)$ patients had stage III disease. Eighty-one patients (16\%) with stage II disease and $196(45 \%)$ patients with stage III disease received adjuvant chemotherapy. In the first decade, 24 (12\%) patients with stage II and 64 (37\%) patients with stage III disease underwent adjuvant chemotherapy. In the latter decade, this increased to 57 (18\%) patients with stage II and $132(51 \%)$ patients with stage III disease. Overall, 389 (40\%) patients had tumours located within the right colon, 285 (29\%) within the left colon and 298 (31\%) had rectal cancer.

In terms of clinicopathological characteristics, right-sided tumour location was associated with older age $(P=0.001)$, higher T stage $(P<0.001)$, high venous invasion $(P=0.021)$, poor tumour differentiation $(P<0.001)$ and MMR deficiency $(P=0.005)$ but was not associated with ASA (American Society of Anesthesiology) grade $(P=0.088)$, nodal stage $(P=0.320)$, marginal involvement $(P=0.466)$, tumour necrosis $(P=0.422)$ or BRAF status $(P=0.566)$. Tumour location was not associated with the administration of adjuvant chemotherapy $(P=0.632)$.

When the tumour microenvironment was considered, there was no association between tumour location and Klintrup-Mäkinen Grade $(P=0.431)$ or tumour stroma percentage $(P=0.543)$. Rightsided tumour location was associated with high $\mathrm{CD}^{+}$within cancer cell nests $(P=0.048)$ but not at the margin $(P=0.160)$. Right-sided tumour location was not associated with $\mathrm{CD}^{+}{ }^{+}$within cancer cell nests $(P=0.666)$ or at the tumour margin $(P=0.194)$.

When the preoperative SIR was considered, right-sided tumour location was associated with a greater SIR as measured by the mGPS $(P<0.001)$ and NPS $(P<0.001)$. Right-sided tumour location was associated with a low preoperative $\operatorname{LMR}(P=0.005$; Table 1$)$.

The relationship between right-sided tumour location and the SIR was examined separately in T1/2, T3 and T4 tumours in the whole cohort. In those patients with $\mathrm{T} 1 / 2$ tumours, right-sided tumour location was not associated with mGPS $(P=0.404)$, NLR
$(P=0.393)$, NPS $(P=0.247)$ or LMR $(P=0.137)$. In those patients with T3 tumours, right-sided tumour location was directly associated with NPS $(P=0.001)$ but was not associated with mGPS $(P=0.119)$, NLR $(P=0.514)$ or LMR $(P=0.299)$. In those patients with T4 tumours, right-sided tumour location was directly associated with mGPS $(P=0.025)$, NPS $(P=0.020)$ and inversely with $\operatorname{LMR}(P=0.015)$.

The median follow-up of survivors at time of censor was 54 months (interquartile range: 28-107 months), with 192 cancerrelated deaths and 188 non-cancer-related deaths. Right-sided tumour location was not associated with CSS $(P=0.377)$ or OS $(P=0.205$; Table 1$)$.

Univariate analysis in colon cancer patients. On univariate analysis in patients with colonic cancer, age $(P=0.001)$, ASA grade $(P<0.001)$, $\mathrm{T}$ stage $(P<0.001), \mathrm{N}$ stage $(P<0.001)$, venous invasion $(P=0.002), \mathrm{CD}^{+}$within nests $(P<0.001)$, mGPS $(P<0.001)$, NLR $(P=0.007)$ and NPS $(P<0.001)$ were associated with reduced CSS. Sex, MMR status, tumour differentiation, LMR and tumour location (that is, left or right colon) were not associated with CSS on univariate analysis. On multivariate analysis, ASA grade (HR 1.91, $P=0.035$ ), N stage (HR 2.96, $P<0.001$ ) and NPS (HR 2.35, $P=0.005$ ) were independently associated with reduced CSS. Overall, 164 (24\%) patients with colon cancer underwent adjuvant chemotherapy. On univariate analysis in this group, T stage $(P=0.006)$, mGPS $(P=0.002)$ and NPS $(P=0.010)$ were associated with reduced CSS. Age, ASA grade, $\mathrm{N}$ stage, tumour differentiation, venous invasion, $\mathrm{CD} 3^{+}$ within cancer nests, NLR, LMR and tumour location were not associated with CSS on univariate analysis. On multivariate analysis mGPS (HR 1.77, $P=0.050$ ) was independently associated with reduced CSS in patients with colon cancer who had undergone adjuvant chemotherapy.

Adjuvant chemotherapy group. There were 275 patients in the adjuvant group who had undergone elective surgery followed by adjuvant chemotherapy with data available regarding tumour subsite. Overall, 96 (35\%) of those patients had primary tumours located within the right colon, 68 (25\%) within the left colon and 111 (40\%) within the rectum. Clinicopathological characteristics are shown in Table 2 . In terms of patient characteristics, tumour location was not associated with age $(P=0.583)$, sex $(P=0.139)$ or ASA grade $(P=0.711)$. Right-sided tumour location was associated with higher $\mathrm{T}$ stage $(P<0.001)$, poor tumour differentiation $(P=0.058)$ and high venous invasion $(P=0.036)$ but not with nodal stage $(P=0.398)$, margin involvement $(P=0.423)$, tumour necrosis $(P=0.779)$, MMR status $(P=0.509)$ or BRAF status $(P=0.460)$.

When the tumour microenvironment was considered, tumour location was not associated with the Klintrup-Mäkinen Grade $(p=0.285)$ or tumour stroma percentage $(P=0.875)$. Right-sided tumour location was associated with high $\mathrm{CD}^{+}$at the margin $(P=0.033)$ and within cancer cells nests $(P=0.012)$ but was not associated with $\mathrm{CD}^{+}$density at the margin $(P=0.586)$ or within cancer cell nests $(P=0.522)$.

There was no association between tumour location and the SIR as measured by mGPS $(P=0.597)$, NLR $(P=0.183)$, NPS $(P=0.066)$ or $\operatorname{LMR}(P=0.128)$.

The median follow-up of survivors at time of censor was 56 months (interquartile range: 32-101), with 60 cancer-related deaths and 27 non-cancer-related deaths. There was no significant difference in terms of CSS $(P=0.302)$ or OS $(P=0.076)$ in the adjuvant group (Table 2).

\section{DISCUSSION}

The results of the present study show that, although right-sided tumour location was associated with factors pertaining to the host, 
Table 1. Associations between right/left/rectal tumours and clinicopathological characteristic, systemic inflammation and the tumour microenvironment in patients undergoing elective surgery for stage I-III colorectal cancer

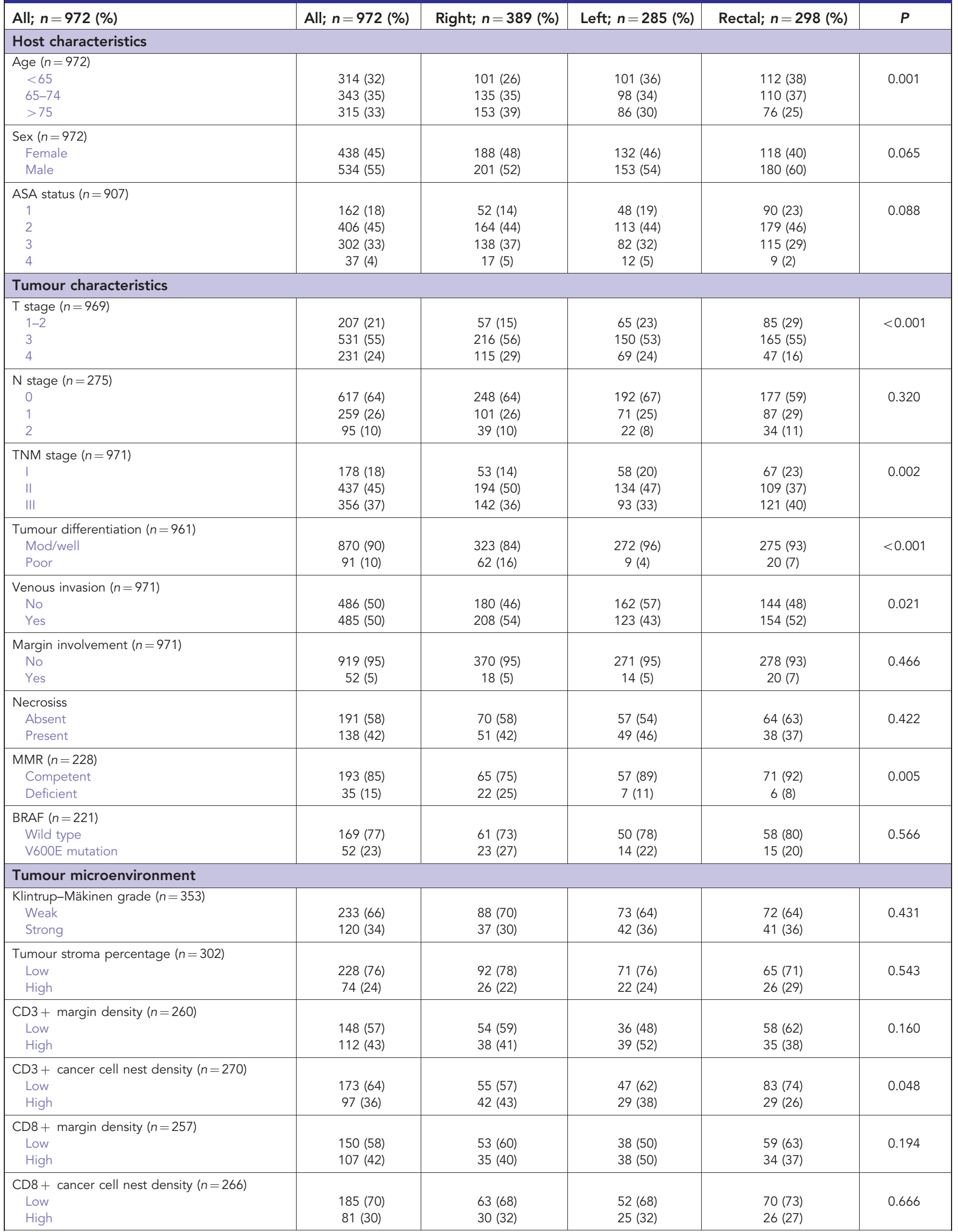




\section{Table 1. (Continued)}

\begin{tabular}{|c|c|c|c|c|c|}
\hline All; $n=972$ (\%) & All; $n=972(\%)$ & Right; $n=389$ (\%) & Left; $n=285$ (\%) & Rectal; $n=298(\%)$ & $P$ \\
\hline $\begin{array}{l}\text { mGPS }(n=926) \\
0 \\
1 \\
2\end{array}$ & $\begin{array}{l}658(71) \\
163(18) \\
105(11)\end{array}$ & $\begin{array}{l}235(64) \\
69(19) \\
62(17)\end{array}$ & $\begin{array}{l}201(75) \\
44(16) \\
25(9)\end{array}$ & $\begin{array}{c}222(77) \\
50(17) \\
18(6)\end{array}$ & $<0.001$ \\
\hline $\begin{array}{l}\text { Neutrophil:lymphoc) } \\
\text { Low } \\
\text { High }\end{array}$ & $\begin{array}{l}708(87) \\
106(13)\end{array}$ & $\begin{array}{l}283(85) \\
51(15)\end{array}$ & $\begin{array}{l}201(90) \\
23(10)\end{array}$ & $\begin{array}{l}224(88) \\
32(12)\end{array}$ & 0.214 \\
\hline $\begin{array}{l}\text { Neutrophil:platelet } 5 \\
0 \\
1 \\
2\end{array}$ & $\begin{array}{c}667(82) \\
116(14) \\
34(4)\end{array}$ & $\begin{array}{c}239(72) \\
71(21) \\
23(7)\end{array}$ & $\begin{array}{c}204(87) \\
23(10) \\
7(3)\end{array}$ & $\begin{array}{l}224(90) \\
22(8) \\
4(2)\end{array}$ & $<0.001$ \\
\hline $\begin{array}{l}\text { Lymphocyte:monocy } \\
\text { Low } \\
\text { High }\end{array}$ & $\begin{array}{l}155(16) \\
817(84)\end{array}$ & $\begin{array}{l}80(21) \\
309(79) \\
\end{array}$ & $\begin{array}{l}39(14) \\
246(86) \\
\end{array}$ & $\begin{array}{c}36(12) \\
262(88)\end{array}$ & 0.005 \\
\hline $\begin{array}{l}\text { 5-year CSS \% (s.e.) } \\
5 \text {-year OS \% (s.e.) }\end{array}$ & & $\begin{array}{l}79(3) \\
66(3) \\
\end{array}$ & $\begin{array}{l}83(3) \\
71(3) \\
\end{array}$ & $\begin{array}{l}76(3) \\
67(3) \\
\end{array}$ & $\begin{array}{l}0.377 \\
0.205\end{array}$ \\
\hline
\end{tabular}

tumour phenotype and features of the tumour microenvironment, it was not prognostic in terms of survival for patients undergoing surgery for stage I-III colon cancer or indeed for those patients within the adjuvant setting. Therefore, the importance of tumour location as a stratification factor in patients with CRC may be secondary to such tumour and host factors.

In the present study, right-sided tumour location was associated with advancing age. Also, consistent with previous studies, rightsided tumour location was associated with a greater proportion of T4 tumours, poor tumour differentiation and presence of venous invasion (Nawa et al, 2008; Weiss et al, 2016; Benedix et al, 2010, 2011). For example, Benedix et al (2010) reported that, in 17641 patients over a 3-year period, right-sided colon cancer was more frequently diagnosed in women, older individuals, those with higher ASA grade, locally advanced and lymph node-positive disease.

In the present study, $25 \%$ of right-sided tumours were MMRdeficient compared with 11 and $8 \%$ of those tumours located within the left colon and rectum, confirming the findings of other studies that report the association of MMR deficiency with right-sided tumour location (Ward et al, 2001). Surprisingly, MMR status was not associated with survival in the full cohort or the adjuvant setting. However, MMR status was only available in a subset of patients $(n=228)$. Previous studies have reported the survival benefit conferred by MMR deficiency in the adjuvant setting (Ward et al, 2001; Tejpar et al, 2009; Sinicrope et al, 2013). For example, the study by Sinicrope et al (2011) 2580 patients in the adjuvant setting reported that the prognostic impact of MMR deficiency depended on tumour site, where deficient MMR cancers in the right colon had favourable outcomes compared with those in the left colon. Therefore, the lack of prognostic value of MMR in the present study is likely due to the small number of patients examined.

In CRC, the local tumour inflammatory response has been reported as having prognostic value independent of tumour stage (Galon et al, 2006; Roxburgh et al, 2009). The relationship between MMR status, systemic inflammation and tumour lymphocytic infiltrate has been examined previously in this cohort. This previous study showed that MMR was associated with the local immune tumour infiltrate and the SIR; however, MMR had relatively poor prognostic value in comparison to these factors (Park et al, 2016). Our results suggest a significant association between right-sided tumour location and high density of activated $\mathrm{T}$ lymphocytes in the whole cohort and in the adjuvant therapy group. This observation may be explained in part by the association of defective MMR with proximal tumour location and in turn with a coordinated, adaptive intratumoural immune response (Park et al, 2016). Nevertheless, the present study is the first to examine the relationship between tumour location and the tumour microenvironment.

The results of the present study showed that for the first time right-sided tumour location was consistently associated with an elevated SIR as measured by mGPS, NPS and LMR. The basis of this observation is not clear. However, in the present study rightsided tumour location was associated with higher $\mathrm{T}$ stage and previous reports suggest that higher $\mathrm{T}$ stage is associated with an increasing SIR; hence, $\mathrm{T}$ stage may be a potential confounder. Therefore, in the present study, the relationship between rightsided tumour location and the SIR was examined separately in T1/ 2, T3 and T4 tumours in the whole cohort. In those patients with T1/2 tumours right-sided tumour location was not associated with the SIR. In contrast, in those patients with T3 and T4 tumours, right-sided tumour location was associated with the SIR (mGPS, NPS and LMR). As the number of patients with T3/T4 tumours was greater in those patients with right-sided tumours, it may be that more tumour invasiveness accounted for the association between right-sided tumour location and the SIR and outcome.

In the present study, there was no association between tumour location and CSS or OS in the full cohort or within the adjuvant group. On univariate analysis in patients with colon cancer, tumour location (that is, right or left) was not associated with CSS or OS or indeed in those patients with colon cancer who had undergone adjuvant chemotherapy. Moreover, results of the present study show that measures of systemic inflammation in patients with colon cancer in the adjuvant and non-adjuvant 
Table 2. Associations between right/left/rectal tumours and clinicopathological characteristic, systemic inflammation and the tumour microenvironment in patients who have undergone adjuvant chemotherapy following elective surgery for stage I-III colorectal cancer

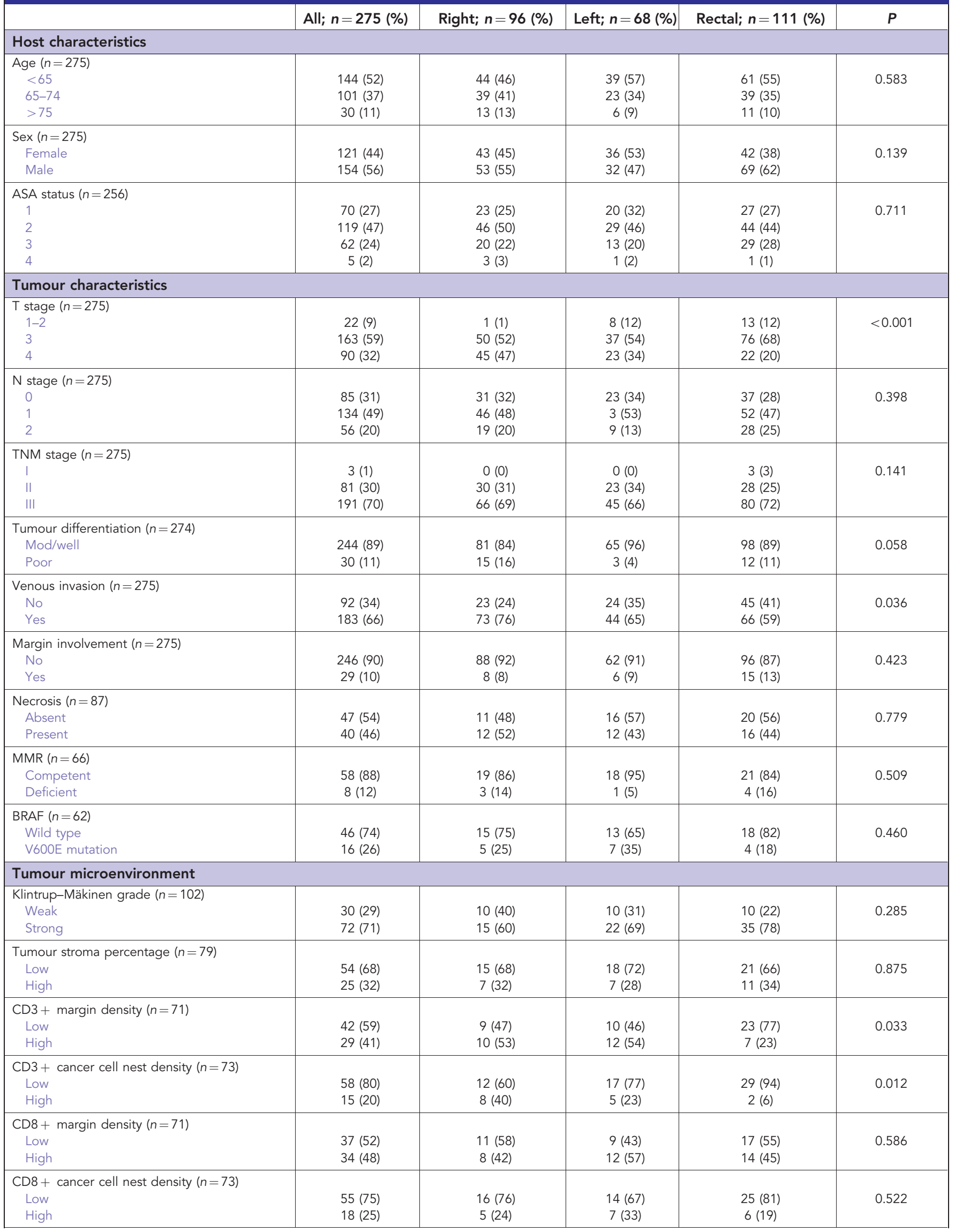




\begin{tabular}{|c|c|c|c|c|c|}
\hline & All; $n=275(\%)$ & Right; $n=96(\%)$ & Left; $n=68(\%)$ & Rectal; $n=111(\%)$ & $P$ \\
\hline \multicolumn{6}{|c|}{ Systemic inflammation } \\
\hline $\begin{array}{l}\text { mGPS }(n=257) \\
0 \\
1 \\
2\end{array}$ & $\begin{array}{c}190(74) \\
47(18) \\
20(8)\end{array}$ & $\begin{array}{l}56(68) \\
19(23) \\
8(9)\end{array}$ & $\begin{array}{l}49(75) \\
11(17) \\
5(8)\end{array}$ & $\begin{array}{c}85(78) \\
17(16) \\
7(6)\end{array}$ & 0.597 \\
\hline $\begin{array}{l}\text { Neutrophil:lymphoc } \\
\text { Low } \\
\text { High }\end{array}$ & $\begin{array}{c}217(87) \\
32(13)\end{array}$ & $\begin{array}{l}80(88) \\
11(12)\end{array}$ & $\begin{array}{c}53(93) \\
4(7)\end{array}$ & $\begin{array}{l}84(83) \\
17(17)\end{array}$ & 0.183 \\
\hline $\begin{array}{l}\text { Neutrophil:platelet } \\
0 \\
1 \\
2\end{array}$ & $\begin{array}{c}189(79) \\
40(17) \\
10(4)\end{array}$ & $\begin{array}{c}63(70) \\
23(26) \\
4(4)\end{array}$ & $\begin{array}{l}46(85) \\
5(9) \\
3(6)\end{array}$ & $\begin{array}{l}80(84) \\
12(13) \\
3(3)\end{array}$ & 0.066 \\
\hline $\begin{array}{l}\text { Lymphocyte:monoc } \\
\text { Low } \\
\text { High }\end{array}$ & $\begin{array}{c}39(14) \\
236(86)\end{array}$ & $\begin{array}{l}17(18) \\
79(82)\end{array}$ & $\begin{array}{c}5(7) \\
63(93)\end{array}$ & $\begin{array}{l}17(15) \\
94(85)\end{array}$ & 0.128 \\
\hline
\end{tabular}

setting were independently prognostic for CSS. Population-based studies (Meguid et al, 2008; Benedix et al, 2010), and outcomes of retrospectively analysed oncological trials of patients with metastatic CRC (Loupakis et al, 2015; Venook et al, 2016) have reported an increase in mortality for right-sided cancers; however, results are conflicting (Weiss et al, 2016; Warschkow et al, 2016). Moreover, they did not adjust for confounders such as the SIR. Therefore, it is of interest that Renfro et al (2017) reported that, in more than 22000 patients from 28 randomised clinical trials of patients with metastatic CRC, an elevated SIR as evidenced by an absolute neutrophil count and the derived NLR was associated with early mortality, whereas KRAS status, patient sex, individual sites of metastases, location of primary tumour (colon $v s$ rectum), and prior chemotherapy use did not appear to have a prognostic role. In addition, a study evaluating the prognostic role of tumour location in stage III colon cancer patients (PETACC- 8 trial) in the context of molecular markers reported that right-sided tumour location was not associated with disease-free survival but was associated with shorter survival after relapse when disease became metastatic and with OS in both MSI-stable and unstable patients (Taieb et al, 2017). However, potential confounding factors such as the SIR was not taken into account.

A potential limitation of the present study was that only $45 \%$ of patients with stage III CRC received adjuvant therapy. It is well recognised that Glasgow Royal Infirmary serves an area of multiple deprivation. As a consequence, many patients have multiple comorbidities and this precludes the use of chemotherapy. Moreover, as the present study spans a period between 1997 and 2016, a period effect should be appreciated. In the present study this effect was demonstrated by the increase in the number of patients with stage III CRC who received adjuvant chemotherapy from $37 \%$ in the first decade to $51 \%$ in the latter decade.

In conclusion, right-sided tumour location was associated with host characteristics, features of the tumour microenvironment and the SIR, but not survival in patients undergoing potentially curative surgery for stage I-III CRC. Future studies investigating the role of tumour location in a prognostic or predictive capacity should be aware of the potential confounding role that inflammatory responses may have in these patients.

\section{CONFLICT OF INTEREST}

The authors declare no conflict of interest.

\section{REFERENCES}

Alley PG, McNee RK (1986) Age and sex differences in right colon cancer. Dis Colon Rectum 29(4): 227-229.

Benedix F, Meyer F, Kube R, Gastinger I, Lippert H (2010) Right- and leftsided colonic cancer - different tumour entities. Zentralbl Chir 135(4): 312-317.

Benedix F, Schmidt U, Mroczkowski P, Gastinger I, Lippert H, Kube R (2011) Colon carcinoma - classification into right and left sided cancer or according to colonic subsite? - Analysis of 29568 patients. Eur J Surg Oncol 37(2): 134-139.

Benedix F, Kube R, Meyer R, Schmidt U, Gastinger I, Lippert H (2010) Comparison of 17,641 patients with right- and left-sided colon cancer: Differences in epidemiology, perioperative course, histology, and survival. Dis Colon Rectum 53(1): 57-64.

IARC (2012) Cancer Incidence and Mortality Worldwide: The GLOBOCAN Project 2012. IARC Cancer Base No. 11 GLOBOCAN 2012 v1.1. International Agency for Research on Cancer: Lyon, France. Available at: http://globocan.iarc.fr/Default.aspx. (Accessed on 9 May 2017).

Cancer Research UK, Bowel Cancer Statistics (2011) Available at: http:// www.cancerresearchuk.org/health-professional/cancer-statistics/statisticsby-cancer-type/bowel-cancer/incidence. (Accessed on 29 August 2017).

Chan JC, Chan DL, Diakos CI, Engel A, Pavlakis N, Gill A, Clarke SJ (2017) the lymphocyte-to-monocyte ratio is a superior predictor of overall survival in comparison to established biomarkers of resectable colorectal cancer. Ann Surg 265(3): 539-546.

Clarke CN, Kopetz ES (2015) BRAF mutant colorectal cancer as a distinct subset of colorectal cancer: clinical characteristics, clinical behavior, and response to targeted therapies. J Gastrointest Oncol 6(6): 660-667.

Cucino C, Buchner AM, Sonnenberg A (2002) Continued rightward shift of colorectal cancer. Dis Colon Rectum 45(8): 1035-1040.

Fleshner P, Slater G, Aufses AH (1989) Age and sex distribution of patients with colorectal cancer. Dis Colon Rectum 32(2): 107-111.

Galon J, Costes A, Sanchez-Cabo F, Kirilovsky A, Mlecnik B, Lagorce-Pagès C, Tosolini M, Camus M, Berger A, Wind P, Zinzindohoué F, Buneval P, Cugnec PH, Trajanoski Z, Fridman WH, Pagès F (2006) Type, density, and location of immune cells within human colorectal tumors predict clinical outcome. Science 313(5795): 1960-1964.

Gelsomino F, Barbolini M, Spallanzani A, Pugliese G, Cascinu S (2016) The evolving role of microsatellite instability in colorectal cancer: a review. Cancer Treat Rev 51: 19-26.

Guthrie GJ, Charles K, Roxburgh CS, Horgan PG, McMillan DC, Clarke SJ (2013) The systemic inflammation-based neutrophil-lymphocyte ratio: experience in patients with cancer. Crit Rev Oncol/Hematol 88(1): 218-230. Klintrup K, Mäkinen JM, Kauppila S, Väre PO, Melkko J, Tuominen H, Tuppurainen K, Mäkelä J, Karttunen TJ, Mäkinen MJ (2005) 
Inflammation and prognosis in colorectal cancer. Eur J Cancer 41(17): 2645-2654.

Li MX, Liu XM, Zhang XF, Zhang JF, Wang WL, Zhu Y, Dong J, Cheng JW, Liu ZW, Ma L, Lv Y (2014) Prognostic role of neutrophil- to- lymphocyte ratio in colorectal cancer: a systematic review and meta- analysis. Int $J$ Cancer 134(10): 2403-2413.

Loupakis F, Yang D, Yau L, Feng S, Cremolini C, Zhang W, Maus MK, Antoniotti C, Langer SJ, Müller T, Hurwitz HI, Saltz L, Falcone A, Lenz HJ (2015) Primary tumor location as a prognostic factor in metastatic colorectal cancer. J Natl Cancer Inst 107(3): dju427-dju427.

McMillan DC (2013) The systemic inflammation-based Glasgow Prognostic Score: a decade of experience in patients with cancer. Cancer Treat Rev 39(5): 534-540.

Meguid RA, Slidell MB, Wolfgang CL, Chang DC, Ahuja N (2008) Is there a difference in survival between right- versus left-sided colon cancers? Ann Surg Oncol 15(9): 2388-2394.

Mesker WE, Junggeburt JM, Szuhai K, de Heer P, Morreau H, Tanke HJ, Tollenaar RA (2007) The carcinoma-stromal ratio of colon carcinoma is an independent factor for survival compared to lymph node status and tumor stage. Cell Oncol 29(5): 387-398.

Nawa T, Kato J, Kawamoto H, Okada H, Yamamoto H, Kohno H, Endo H, Shiratori Y (2008) Differences between right- and left-sided colon cancer in patient characteristics, cancer morphology and histology. $J$ Gastroenterol Hepatol 23(3): 418-423.

Park JH, Watt DG, Roxburgh CS, Horgan PG, McMillan DC (2016) Colorectal cancer, systemic inflammation, and outcome: staging the tumor and staging the host. Ann Surg 263(2): 326-336.

Park JH, Powell AG, Roxburgh CS, Horgan PG, McMillan DC, Edwards J (2016) Mismatch repair status in patients with primary operable colorectal cancer: associations with the local and systemic tumour environment. $\mathrm{Br} J$ Cancer 114(5): 562-570.

Renfro LA, Goldberg RM, Grothey A, Sobrero A, Adams R, Seymour MT, Heinemann V, Schmoll HJ, Douillard JY, Hurwitz H, Fuchs CS, Diaz-Rudio E, Porschen R, Tournigand C, Chibaudel B, Hoff PM, Kabbinavar FF, Falcone A, Tebbutt NC, Punt CJA, Hecht JR, Souglakos J, Bokemeyer C, Can Cutsem E, Saltz L, de Gramont A, Sargent DJ (2017) Clinical calculator for early mortality in metastatic colorectal cancer: an analysis of patients from 28 clinical trials in the Aide et Recherche en Cancérologie Digestive Database. J Clin Oncol 35(17): 1929-1937.

Richards CH, Roxburgh CS, Powell AG, Foulis AK, Horgan PG, McMillan DC (2014) The clinical utility of the local inflammatory response in colorectal cancer. Eur J Cancer 50(2): 309-319.

Roxburgh CS, McMillan DC, Anderson JH, McKee RF, Horgan PG, Foulis AK (2010) Elastica staining for venous invasion results in superior prediction of cancer-specific survival in colorectal cancer. Ann Surg 252(6): 989-997.

Roxburgh CS, Salmod JM, Horgan PG, Oien KA, McMillan DC (2009) Tumour inflammatory infiltrate predicts survival following curative resection for node-negative colorectal cancer. Eur J Cancer 45(12): 2138-2145.

Roxburgh CS, McMillan DC (2012) The role of the in situ local inflammatory response in predicting recurrence and survival in patients with primary operable colorectal cancer. Cancer Treat Rev 38(5): 451-466.
Sinicrope FA, Foster NR, Thibodeau SN, Marsoni S, Monges G, Labianca R, Kim GP, Yothers G, Allegra C, Moore MJ, Gallinger S, Sargent DJ (2011) DNA mismatch repair status and colon cancer recurrence and survival in clinical trials of 5-fluorouracil-based adjuvant therapy. J Natl Cancer Inst 103(11): 863-875.

Sinicrope FA, Mahoney MR, Smyrk TC, Thibodeau SN, Warren RS, Bertagnolli MM, Nelson GD, Goldberg RM, Sargent DJ, Alberts SR (2013) Prognostic impact of deficient DNA mismatch repair in patients with stage III colon cancer from a randomized trial of FOLFOX-based adjuvant chemotherapy. J Clin Oncol 31(29): 3664-3672.

Taieb J, Kourie HR, Emile JF, Malicot KL, Balogoun R, Tabernero J, Mini E, Folprecht G, Van Laethem JL, Mulot C, Bouche O, Aparicio T, Michel P, Thaler J, Bridgewater J, Van Cutsem E, Perkins G, Lepage C, Salazar R, Puig PL (2017) Prognostic value of of primary tumor location in stage III colon cancer is associated with RAS and BRAF mutational status. Ann Oncol 28(suppl 3): 3515-3515. Available at: (https://doi.org/10.1093/ annonc/mdx262.014).

Tejpar S, Bosman F, Delorenzi M, Fiocca R, Yan P, Klingbiel D, Dietrich E, Van Cutsem E, Labianca R, Roth A (2009) Microsatellite instability (MSI) in stage II and III colon cancer treated with 5FU-LV or 5FU-LV and irinotecan (PETACC 3-EORTC 40993- SAKK 60/00 trial). J Clin Oncol 27(suppl 15): 4001-4001.

Venook P, Niedzwiecki D, Innocenti F, Fruth B, Greene C, O'Neil BH, Shaw JE, Atkins JN, Horvath LE, Polite BN, Meyerhardt JA, O’Reilly EM, Goldberg RM, Hoch HS (2016) Impact of primary tumor location on overall survival and progression-free survival in patients with metastatic colorectal cancer: analysis of CALGB/SWOG 80405 (Alliance). J Clin Oncol 34(suppl 15): 3504-3504.

Ward R, Meagher A, Tomlinson I, O'Connor T, Norrie M, Wu R, Hawkins N (2001) Microsatellite instability and the clinicopathological features of sporadic colorectal cancer. Gut 48(6): 821-829.

Warschkow R, Sulz MC, Marti L, Tarantino I, Schmied BM, Cerny T, Güller U (2016) Better survival in right-sided versus left- sided stage I - III colon cancer patients. BMC Cancer 16: 554.

Watt DG, Proctor MJ, Park JH, Horgan PG, McMillan DC (2015) The neutrophil-platelet score (NPS) predicts survival in primary operable colorectal cancer and a variety of common cancers. PLoS One 10(11): e0142159.

Woo HD, Kim K, Kim J (2015) Association between preoperative C-reactive protein level and colorectal cancer survival: a meta-analysis. Cancer Causes Control 26(11): 1661-1670.

Weiss JM, Pfau PR, O'Connor ES, King J, LoConte N, Kennedy G, Smith MA (2016) Mortality by stage for right- versus left-sided colon cancer: analysis of surveillance, epidemiology, and end results - medicare data. J Clin Oncol 29(33): 4401-4409.

This work is published under the standard license to publish agreement. After 12 months the work will become freely available and the license terms will switch to a Creative Commons AttributionNonCommercial-Share Alike 4.0 Unported License. 